\title{
Criatividade na educação infantil: contribuições da psicologia cultural para a investigação de concepções e práticas de educadores
}

Mônica Souza Neves-Pereira. Universidade de Brasília. Angela Uchoa Branco. Universidade de Brasília.

\section{Resumo}

O presente trabalho investigou as concepções e práticas de professores de educação infantil relacionadas à promoção e/ou inibição da criatividade dos seus alunos. O estudo foi realizado em duas escolas privadas de Educação Infantil de Brasília/DF, com duas professoras e seus alunos entre 5-6 anos. Os dados foram construídos por meio de observações diretas, gravações em vídeo de atividades planejadas pelas docentes e entrevistas. Utilizou-se análise microgenética para investigar as interações professora-crianças gravadas em vídeo e a análise interpretativa das entrevistas. Os resultados apontam para a inadequação dos conceitos e concepções de criatividade, por parte dos professores, e o quanto isto interferiu negativamente nas práticas pedagógicas voltadas para o fomento do potencial criativo.

Palavras-chave: criatividade; psicologia cultural; desenvolvimento humano; educação.

\begin{abstract}
Creativity in preschool: culture psychology contributions to the investigation of teachers' conceptions and practices. The study investigated concepts and practices of early education teachers regarding the promotion and/or inhibition of children's creativity. It was carried out in two private preschools in Brasilia with two teachers and their five to six years-old pupils. Data construction was based on direct observations, video records of activities planned by the teachers, and interviews. A microgenetic approach was used to analyze teacher-students interactions recorded in video, and an interpretive approach was used to analyze the interviews. Results reveal the inappropriateness of concepts and conceptualizations about creativity by the teachers, and how this had a negative impact over pedagogical practices oriented to foster creativity.
\end{abstract}

Keywords: creativity; cultural psychology; human development; education.

\section{Resumen}

Creatividad en la educación infantil: contribuciones de la psicología cultural para la investigación de concepciones y prácticas de educadores. El presente trabajo investigó las concepciones y prácticas de profesores de Educación Infantil relacionadas a la promoción y/o inhibición de la creatividad de sus estudiantes. El estudio fue realizado en dos escuelas privadas de Educación Infantil de Brasilia/DF, con dos profesoras y sus alumnos entre cinco y seis años. Los datos fueron construidos por medio de observaciones directas, grabaciones en video de actividades planeadas por las docentes y entrevistas. Se utilizó un análisis microgenético para investigar las interacciones profesora-alumnos grabadas en video y un análisis interpretativo de las entrevistas. Los resultados señalan una inadecuación de los conceptos y concepciones sobre creatividad por parte de las profesoras; interfiriendo negativamente en la prácticas pedagógicas relacionadas a la promoción del potencial creativo.

Palabras clave: creatividad; psicología cultural; desarrollo humano; educación. 
A predominância de modelos que investigam a criatividade por meio de uma perspectiva positivista e experimental tem sido fortemente evidenciada na psicologia. Em grande parte dos estudos, encontramos o fenômeno criativo analisado quantitativamente, com suas dimensões constituintes apartadas do todo, sem que haja, necessariamente, a construção de um corpo teórico sistêmico e integrado, com enfoque desenvolvimental, que explique a criatividade em sua complexidade e abrangente constituição (Batey, Furnham, \& Safiullina, 2010; Hoff \& Carlsson, 2011). Compreendida como fenômeno humano, a criatividade pode e deve ser investigada em sua gênese e processo de desenvolvimento, com foco no sujeito e suas dinâmicas de inserção na cultura por meio de reguladores semióticos que a circundam e mobilizam ao longo da ontogênese. Analisar o fenômeno criativo em uma perspectiva de desenvolvimento humano permite o resgate do sujeito que cria em sua trajetória ontogenética, além de considerar a dimensão sociocultural, histórica e temporal como aspectos constitutivos do sujeito e suas potencialidades, onde se inscreve a capacidade de criar. Neste artigo, nossa proposta consiste em investigar a criatividade a partir de uma abordagem sociogenética (Connery, John-Steiner, \& Marjanovic-Shane, 2010; Lindqvist, 2003; Smolucha, 1992; Vygotsky, 2009) com destaque para as contribuições da psicologia cultural (Branco \& Valsiner, 2012; Rogoff, 2003; Valsiner, 2012a, 2012b).

A psicologia cultural lida com os fenômenos psicológicos que caracterizam a condição humana e que se desenvolvem somente porque os sujeitos estão imersos em contextos culturais. Sendo assim, tudo o que é da ordem sociocultural interfere e mobiliza, de modo decisivo, a construção das rotas de desenvolvimento de cada indivíduo (Branco \& Valsiner, 2012; Valsiner, 2012a, 2012b). A criatividade, vista como função psicológica, tem suas trajetórias de desenvolvimento marcadas pelos mesmos processos, dinâmicas, limites e dimensão temporal que caracterizam as demais funções, portanto, apresenta credenciais para ser investigada pelos mesmos caminhos teóricos e metodológicos (Neves-Pereira, 2007).

Vygotsky deu uma contribuição significativa para o campo da criatividade ao inseri-la em uma perspectiva de desenvolvimento humano (Kosulin, 1994; Lindqvist, 2003; Smolucha, 1992; Vygotsky, 2009). Falar de criatividade, na perspectiva de Vygotsky, inclui a assunção de que sua gênese atende aos mesmos princípios das outras funções psicológicas. Os contextos social e histórico ascendem como influentes no surgimento do potencial criador, dando origem a uma relação particular, onde a criatividade emerge da cultura, por meio das rotas desenvolvimentais construídas pelos sujeitos, e a ela é devolvida na forma de resultados criativos. Para Vygotsky (2009) o desenvolvimento da criatividade é fundamentalmente orientado pelo contexto cultural ao qual pertence o sujeito agente do ato criativo. Sua expressão criativa individual, porém, reflete a influência do coletivo, é obra do grupo, da dimensão social, onde o sujeito, como agente, apenas exteriorizou o desejo, necessidade ou pensamento oriundo e emergente da cultura. Criatividade surge, então, do domínio sociocultural como produto da interação do sujeito com seu ambiente, impulsionado neste percurso pelos processos de desenvolvimento e aprendizagem. Uma vez definida pela cultura, passa a ser elemento formador dessa mesma cultura. Emerge como uma via de mão-dupla de onde se cria e onde se passa a criar (Neves-Pereira, 2007).

Lindqvist discute uma "Teoria da Criatividade" proposta por Vygotsky argumentando que este modelo inicia com uma abordagem bem realista da função psicológica da imaginação e finaliza com uma visão dialética da mesma função, ampliada por meio do processo de aquisição de conceitos. Para esta autora, Vygotsky entendia a imaginação como atividade mental totalmente compatível com a realidade. Os conteúdos que constituem a imaginação são retirados da realidade e, posteriormente, transformados e/ou recombinados pela função imaginativa, construindo novas realidades. Sendo assim, a atividade criativa, originária da função da imaginação, é uma ação relacionada com a interpretação da realidade feita pelos sujeitos e depende, diretamente, das experiências do homem em contato com sua realidade cultural objetiva e subjetiva. A imaginação está ligada à emoção. Ela retira fragmentos da realidade e, por meio de novas significações destes fragmentos, devolve à cultura leituras renovadas desta mesma realidade. Esta é a essência do processo criativo na concepção de Vygotsky. A imaginação é, ao mesmo tempo, intelectual e emocional, o que também caracteriza a criatividade (Lindqvist, 2003; Vygotsky, 2009).

Ao considerar o desenvolvimento humano como processo multidimensional (psicológico, cultural, histórico, social e temporal) e sistêmico, a psicologia cultural defende um modelo onde o sujeito internaliza de maneira ativa os elementos culturais a partir de uma via de mão-dupla, em uma dinâmica bidirecional, por meio de uma construção conjunta. Aspectos da cultura pessoal (sujeito) e da cultura coletiva (elementos culturalmente 
partilhados) vão se mesclar, dando origem a novas configurações subjetivas e coletivas (Valsiner, 2012b). A mediação semiótica causa/possibilita esta aproximação e distanciamento concomitante entre sujeito e cultura, construindo campos semióticos autorreguladores que atuam em uma dinâmica de separação inclusiva, transformando, mutuamente, sujeito e cultura em um tempo real. O que emerge do encontro entre sujeito e cultura é sempre algo novo, original. O sentido da criatividade é parte deste modelo teórico, ao surgir como marca ontogenética que caracteriza a singularidade humana.

A dinâmica dos processos desenvolvimentais, de acordo com a psicologia cultural, relaciona-se com a dimensão da imprevisibilidade do fenômeno. O sujeito se desenvolve em um processo de construção conjunta de suas estruturas psicológicas em parceria com os "outros sociais", processo este que o orienta para determinadas metas. Essas metas são sugestivas, proporcionando um leque de opções sociais que o indivíduo tanto pode internalizar de maneira ativa, quanto negar. Uma das características dessas metas sociais é o seu caráter múltiplo e difuso, o que implica em inúmeras possibilidades de trajetórias. Como o processo é coconstruído e o sujeito tem papel ativo, fica impossível determinar com precisão quais rotas serão escolhidas e por quais caminhos o indivíduo dirigirá seu percurso desenvolvimental. Nessa perspectiva, prever os frutos do desenvolvimento torna-se tarefa complicada, de certa forma quase probabilística (Valsiner, 2012b). O mesmo processo desenvolvimental é válido para a compreensão da criatividade.

$\mathrm{Na}$ ótica da psicologia cultural, a internalização da cultura se caracteriza pela marca da subjetividade, com o indivíduo atuando diretamente na construção de sua cultura pessoal. A transformação das mensagens culturais ocorre em tempo real, gerando uma dimensão desenvolvimental da própria cultura em íntima articulação com o desenvolvimento da pessoa, o que caracteriza o fenômeno psicológico como processo (Valsiner, 2012a, 2012b). Os dispositivos semióticos construídos pelo sujeito em sua trajetória ontogenética funcionam como reguladores de sua experiência no aqui e agora (dimensão microgenética) configurando, em médio e longo prazo, uma bagagem semiótica que o sujeito carregará e transformará, simultaneamente, ao longo de seu curso de vida (relações mesogenéticas e contexto macrogenético). A regulação operada pelos signos vai criar campos limitadores e facilitadores da experiência humana, permitindo ao sujeito agir, pensar, sentir e criar em diferentes níveis de simbolização e de experiência (Valsiner, 2012b).
Ao analisarmos a criatividade à luz da psicologia cultural nos deparamos com desafios de ajustes conceituais e também com a necessidade de certa ousadia na integração dos temas. O modelo de desenvolvimento das funções psicológicas proposto pela psicologia de Valsiner serve ao entendimento da origem da criatividade em sua ontogênese. É possível visualizar, refletir e aprofundar ideias e proposições sobre o desenvolvimento da criatividade a partir dos complexos processos que envolvem sujeito e cultura nesta dança dialética que configura o desenvolvimento humano. Criatividade, entretanto, apresenta aspectos diferenciais em sua expressão. É um fenômeno que não pode ser compreendido como mera ação adaptativa, pois se caracteriza por ser ação combinatória, onde diversos elementos simbólicos produzidos pela cultura são reorganizados e reconstruídos, gerando novos produtos e contribuições culturais (Neves-Pereira, 2007).

São objetivos deste estudo: (1) Elaborar, com base na literatura especializada e em observações diretas do contexto pré-escolar, um modelo de indicadores de criatividade adequado à análise de processos facilitadores e inibidores da criatividade em sala de aula; (2) Identificar e analisar os indicadores de criatividade (IC) presentes em situações estruturadas pelas duas professoras participantes do estudo, com o objetivo de promoção de criatividade em sala de aula; (3) Identificar e analisar, por meio dos IC, as atividades desenvolvidas no contexto da rotina diária da turma e das estratégias de interação social relacionadas à promoção ou à inibição de comportamentos criativos entre as crianças e (4) Investigar as concepções das professoras acerca da criatividade, suas características, processos e dinâmica.

\section{Método}

\section{Participantes do estudo}

Duas professoras da Educação Infantil (turmas entre 5-6 anos) de duas escolas privadas e situadas no Plano Piloto - Brasília/DF participaram deste estudo. As duas escolas localizavam-se em áreas nobres de Brasília e atendiam a alunos de classe média alta. A escolha das escolas atendeu a três critérios, a saber: (a) oferta de Educação Infantil, (b) indicação, por parte da Direção e demais educadores, da professora considerada a mais criativa no contexto escolar e (c) permissão para imersão da pesquisadora em cada escola por seis meses. $\mathrm{Na}$ Escola A, a turma selecionada era composta por 16 alunos, sendo 10 meninas e seis meninos. A professora 
da Escola A, doravante denominada PA, tinha 26 anos de idade e formação em magistério (nível médio). Na Escola B, a turma observada era composta por nove alunos, sendo seis do sexo feminino e três do sexo masculino. A professora da Escola B, doravante denominada PB, tinha 29 anos, também era normalista e cursava Pedagogia na Universidade de Brasília.

\section{Instrumentos}

Os instrumentos utilizados na investigação foram: (a) Videogravação das atividades estruturadas pelas professoras com o objetivo específico de desenvolvimento da criatividade dos alunos e (b) Entrevista semiestruturada com as professoras. Para realização da análise microgenética das videogravações foram construídos recursos metodológicos aqui denominados "Indicadores de Criatividade". As entrevistas foram tratadas por meio de Análise Interpretativa (Gaskell, 2003) e contabilizaram 20 questões diversas sobre criatividade.

\section{Os indicadores de criatividade}

Para fins de análise do contexto e das interações sociais das atividades estruturadas pelas professoras, foram construídos os Indicadores de Criatividade (IC). Os IC foram elaborados a partir de categorias cognitivas, personológicas e socioculturais trabalhadas na literatura sobre Criatividade (Amabile, 1996; Eysenck, 1997; Tardif \& Sternberg, 1988). A escolha pela construção de uma nova metodologia de análise para o estudo da criatividade e seus aspectos componentes foi feita, especialmente, para atender a uma visão diferenciada do fenômeno criativo, aqui compreendido como uma função psicológica que tem seu desenvolvimento circunscrito às mesmas regras desenvolvimentais presentes na ontogênese. Criatividade, neste estudo, não é compreendida como fenômeno partido em categorias isoladas que ora privilegiam o sujeito criativo, ora o processo ou mesmo, em outros momentos, as circunstâncias ambientais que cercam este sujeito. A construção dos IC ocorreu em consonância com esta visão de criatividade e com o propósito de auxiliar, ao longo do processo de análise microgenética, a identificação das dinâmicas e contextos interativos em sala de aula promotores ou inibidores da criatividade. Os IC articulam as categorias constitutivas que caracterizam a expressão criativa propondo um modelo integrado e processual do desenvolvimento da criatividade.

Os Indicadores de Criatividade - IC foram divididos em dois níveis integrados e complementares. Os IC de Nível 1 são composto por três grupos categoriais que atuam, de modo relevante, nas construção de processos criativos, a saber: (1) Categorias Cognitivas, (2) Categorias Personológicas e (3) Categorias Socioculturais. Dentre os Indicadores Cognitivos constam seis itens que caracterizam o funcionamento cognitivo típico de pessoas criativas. Os Indicadores Personológicos são compostos por 12 itens vinculados aos processos de visão de si mesmo ou desenvolvimento do self. Os Indicadores Socioculturais são representados por 14 itens relacionados às dimensões socioculturais que mais interferem na promoção da criatividade. Os itens que compõem as três categorias de IC de nível 1 estão descritos nas Tabelas 2 e 3. Os IC de Nível 2 se expressam em duas categorias: IPC (Indicadores promotores de criatividade) e IIC (Indicadores inibidores da criatividade).

Os IC de Nível 1 investigaram quais fatores favorecedores da criatividade foram trabalhados pelas professoras nas atividades estruturadas realizadas em sala de aula com os alunos e com o propósito específico de fomento do potencial criativo das crianças. Os IC de Nível 2 foram utilizados na análise microgenética das atividades estruturadas com o propósito de identificar e analisar como as professoras utilizaram os IC de Nível 1: para promover a criatividade, para impedir a criatividade ou se não houve utilização dos IC.

\section{Procedimentos}

A construção dos dados obedeceu à seguinte ordem para as duas escolas: (a) gravação em vídeo de uma atividade estruturada por cada professora de cada escola, com cerca de 30 minutos de duração cada, com o objetivo específico de "desenvolver habilidades criativas em seus alunos" e (b) entrevistas com as respectivas professoras em cada escola, gravadas em áudio.

\section{Resultados}

As duas Atividades Estruturadas (Escola A e Escola B) foram gravadas em vídeo, transcritas em episódios e analisadas em nível microgenético. Foram selecionados episódios específicos para a discussão dos resultados. Os critérios de seleção dos episódios foram baseados em momentos interativos professor-criança e criança-criança onde ações promotoras e/ou inibidoras da criatividade apresentaram significados relevantes. $\mathrm{Na}$ Tabela 1 constam detalhamentos das atividades estruturadas desenvolvidas pelas professoras PA e PB. 
Tabela 1. Detalhamento das Atividades Estruturas das Duas Professoras - PA e PB

$\mathrm{PA}^{*}$

Descrição da atividade: Montagem de um cachorrinho por meio de dobraduras de papel. Após a montagem, cada criança recebia uma folha de papel pardo onde o cachorrinho deveria ser colado e onde, também, deveria ser desenhado o local onde o cachorrinho estaria. As crianças receberam os papeis para a dobradura já cortados e previamente dobrados, com a marca das dobras. Cada criança recebeu três papeis: o primeiro correspondia à cabeça do cachorrinho; o segundo correspondia ao corpo e o terceiro era o papel pardo onde o cachorrinho, pronto, deveria ser colado. As crianças desta turma já tinham realizado esta mesma atividade anteriormente, com exceção do uso do papel pardo e do desenho do local onde o cachorrinho poderia estar.

Tempo da sessão: 00:30:59'

Material utilizado: Papel, cola, lápis de cor. O material foi preparado por PA no balcão da sala de aula, sem a participação das crianças.

A atividade estruturada da Escola A foi subdividida em 24 episódios analisados em nível microgenético.

Os episódios 13, 14, 15 e 23 foram selecionados para ilustração dos resultados.

$\mathrm{PB}^{* *}$

Descrição da atividade: Tarefa de pintura livre sobre uma cartolina previamente preparada pela professora. Foi a primeira vez que as crianças realizaram esta tarefa. Cada criança recebeu uma cartolina com um círculo pintado. Cada círculo tinha o tamanho aproximado da boca de um copo de água de tamanho normal, pintado em locais diferentes no papel: centro, canto superior direito, canto superior esquerdo etc. A tarefa consistia em criar, utilizando o círculo, um desenho livre de acordo com o desejo e a imaginação de cada um. $O$ dado relevante da tarefa era utilizar o círculo como parte do desenho e/ou pintura produzida.

Tempo da sessão: 00:30:26'

Material utilizado: (a) Uma cartolina preta com um círculo branco pintado sobre ela. Cada cartolina continha o círculo branco em uma posição diferente: centro, canto superior direito, canto inferior esquerdo etc.; (b) Diversas tábuas de bater carne com tinta guache em diferentes cores para uso coletivo; (c) Pincéis; (d) Copos de plástico com água para limpeza dos pincéis; (e) Panos brancos para limpeza dos pincéis.

A atividade estruturada da Escola A foi subdividida em 20 episódios analisados em nível microgenético.

Os episódios 6, 7, 8, 12, 16 foram selecionados para ilustração dos resultados.

* Participaram da atividade estruturada na Escola A 12 crianças, sendo 7 meninas e 5 meninos; ${ }^{* *}$ Participaram da atividade estruturada na Escola B 6 crianças, sendo 5 meninas e 1 menino.

\section{Atividade estruturada da escola A - PA - episódios selecionados}

A Atividade Estruturada por PA deu origem a 24 episódios analisados microgeneticamente. Selecionamos aqui, para efeito de ilustração, apenas três episódios (Episódios 13, 14 e 15)

Episódio 13: O quadrado que vira triângulo. Duração do Episódio: 51 segundos. PA inicia a dobradura da cabecinha do cachorro em forma de triângulo na frente das crianças. Ela insiste que a forma triangular é que define uma cabeça de cachorro: Cachorro tem cara de quadrado? Um menino diz: Não! PA: Cachorro tem cara de triângulo? Poucas crianças respondem que não... A tarefa proposta é de natureza padronizada e as crianças não tem autonomia para criar nada novo. PA diz, Ah, agora a gente vai ter que arrumar esse triângulo aqui né? Arrumaram? PA dirige-se a uma menina em especial: Tem que fazer um triângulo, Neusa! O seu ainda tá quadrado e eu quero um triângulo.

Análise do episódio 13. IPC: não foram registrados. IIC: PA controlou com firmeza o resultado da atividade, cobrando das crianças o triângulo como resultado da tarefa da dobradura 1. PA também recriminou uma criança por diversificar seu espaço de desenho e criação.

Episódio 14: Eu já sabia! Duração do Episódio: 1 minuto e 3 segundos. PA explica, detalhadamente, o modo como as crianças devem fazer a dobradura da cabeça do cachorro. Ela faz questão que as crianças visualizem o que ela faz e reproduzam o modelo com exatidão. Enquanto dobra o papel, PA reafirma: Aqui está um quadrado! Vamos fazer um triângulo? Ou então, Eu quero essa pontinha viradinha pra barriguinha de vocês, ó! PA se preocupou em garantir que o resultado fosse idêntico para todos. As crianças dizem: Isso é fácil! Eu já sabia!, Pois a tarefa havia sido feita anteriormente.

Análise do episódio 14. IPC: PA permite a uma criança que não faça parte da tarefa (dobrar a língua do cachorro) respeitando sua vontade. PA permite que o menino desenhe na folha da dobradura, ao invés de seguir as regras de dobrar a folha, respeitando sua motivação para desenhar. Há respeito pela autonomia e independência de ação da criança. IIC: A Atividade é de reprodução e sem espaço para a criatividade, com ênfase excessiva nas regras e na forma de realizar a tarefa, que deveria ser igual para todas as crianças. PA faz.perguntas óbvias e irrelevantes, as quais não geram interesse ou motivação. Suas verbalizações não representam desafios ou sugestões inovadoras.

Episódio 15: O corpo do cachorrinho. Duração do Episódio: 56 segundos. PA começou este episódio dizendo que iria entregar o corpo do cachorrinho e que a partir dali eles iriam fazer diferente. Ela não especificou o que era este "diferente" e nada de diferente, de fato, 
aconteceu neste episódio. A dobradura correspondente ao corpo do cachorro já vinha pronta. Além de já estar dobrada, também continha um recorte arredondado na base do triângulo que sinalizava as perninhas com o espaço para a dobra do rabinho do cachorrinho. Uma menina, ao receber sua dobradura, disse: Mas é igualzinho! Outra menina também falou: Tia, eu já vou fazer! A resposta de PA à menina reafirma a falta de criatividade inerente àquela tarefa: É, esse foi igualzinho àquele que nós fizemos. PA perguntou se cachorro tinha rabo. As crianças responderam unanimemente que sim. Ninguém questionou distintas raças de cachorros sem rabo ou cujo rabo é curto, ou sequer aparecem. Ninguém considerou a possibilidade do cachorro ter tido o rabo cortado. PA trabalhou, o tempo todo, com um modelo genérico de cachorro, com quatro patas, rabo, duas orelhas e uma língua. Várias crianças se anteciparam à PA na realização desta etapa da tarefa. Paulo fez a dobra do rabo do cachorro antes mesmo de PA mostrar como deveria ser feito. Ele disse aos amigos da mesa onde estava sentado: Aqui ó, eu sei fazer!

Análise do episódio 15. IPC: não foram registrados. IIC: As crianças, de um modo geral, também verbalizaram que já conheciam a tarefa proposta, mas PA não deu atenção a estas expressões. Ela mesma sabia que a tarefa já era conhecida pelas crianças e não considerou as reações expressas com relação à tarefa, outra manifestação de rigidez e desconhecimento do conceito de criatividade. PA dá ênfase à convergência e reprodução de processos e ações. Dois meninos se anteciparam e realizaram a tarefa antes de PA explicar as regras. Eles demonstraram conhecer a tarefa e PA não se mobilizou com relação a isto.

A Tabela 2 apresenta os Indicadores de Criatividade dos Níveis 1 e 2 presentes ao longo da Atividade Estruturada por PA.

\section{Atividade estruturada da escola B - PB - episódios selecionados}

A Atividade Estruturada por PB deu origem a 20 episódios analisados microgeneticamente. Selecionamos aqui, para efeito de ilustração, apenas três episódios (Episódios 7, 8 e 16).

Episódio 7: Quero fazer em cima! Duração do Episódio: 2 minutos e 13 segundos. A atividade de pintura continuava se desenvolvendo com as crianças bastante motivadas para a tarefa. Ivete reclamou por não ter sido atendida na sua proposta. Alice disse que a forma de Ivete, virada de cabeça para baixo, ficava igual à dela. Ivete parecia querer uma cartolina semelhante à de Alice. PB chamou a atenção de Ivete para que ela se concentrasse no seu trabalho, dizendo que seria meIhor deixar o trabalho de Alice de lado e se concentrar no seu. Ivete, inconformada, verbalizou mais uma vez: Mas eu quero fazer em cima essa coisa aqui (e apontou o círculo novamente). PB reforçou que ela tinha escolhido uma cartolina específica e que agora não poderia mudar. Ivete deixou de reclamar e retornou ao seu trabalho. $\mathrm{O}$ comportamento de PB, do ponto de vista da criatividade, foi inibidor por demonstrar inflexibilidade.

Análise do episódio 7. IPC: A tarefa era de natureza criativa e abriu espaço para a imaginação combinatória. PB incentivou as crianças, o tempo todo, a produzirem de modo original. Ela não interviu na produção das crianças, respeitando suas opções e seus tempos de criação. IIC: $\mathrm{PB}$, novamente, impediu Ivete de modificar a estrutura da sua tarefa. A professora impediu a quebra das regras e não abriu espaço para novas propostas de trabalho neste episódio.

Episódio 8: Não é para forçar o pincel. Duração do Episódio: 1 minuto e 48 segundos. PB disse: "É... vamo... é... Breno... ó, o que eu falei... se a gente força muito o pincel, ele abre inteirinho e nem sempre a gente consegue dar a forma que a gente deseja. Se a gente trabalha com mais suavidade... isso...". Breno estava forçando o pincel na cartolina e parou de fazer isso assim que PB sinalizou. PB insistiu com Breno sobre o modo correto de utilizar o pincel. Ao estabelecer este limite, de certa forma, impediu que Breno pudesse experimentar várias possibilidades com o pincel e a tinta, visto que pinceladas fortes podem fazer a diferença, considerando a qualidade final do trabalho artístico produzido. Esta possibilidade não foi considerada por PB.

Análise do episódio 8. IPC: PB promoveu indicadores de ordem cognitiva, com destaque para a solução de problemas. Ela motivou Breno a buscar soluções para uma situação construída por ele e se disponibilizou a ajudá-lo a experimentar novas possibilidades para aquele determinado problema. PB não interferiu nos diálogos das crianças, respeitando os assuntos que surgiram neste episódio. IIC: PB limitou as possibilidades de uso do material de trabalho ao estabelecer regras para a utilização dos pincéis.

Episódio 16: Sua menina vai ter rosto? Duração do Episódio: 1 minuto e 8 segundos... PB questionou Breno 
Tabela 2. Indicadores de Criatividade de Níveis 1 e 2 Presentes ao Longo da Atividade Estruturada por PA ( $n=24$ episódios)

\begin{tabular}{|c|c|c|c|}
\hline Indicadores de Ordem Cognitiva & IPC-Promoção & IIC-Inibição & IPC + ICC no mesmo episódio \\
\hline Fluência & - & 2 & - \\
\hline Flexibilidade & - & 2 & - \\
\hline Originalidade & - & 1 & - \\
\hline Elaboração & - & 3 & - \\
\hline Competência para Solucionar Problemas & - & 3 & - \\
\hline Imaginação Combinatória & - & - & - \\
\hline TOTAL & - & 11 & - \\
\hline Indicadores de Ordem Personológica & IPC-Promoção & IIC-Inibição & IPC + ICC no mesmo episódio \\
\hline Motivação Intrínseca & 3 & 16 & - \\
\hline Não-Conformismo & 1 & 6 & - \\
\hline Autoestima & 1 & 5 & - \\
\hline Interesses Amplos & - & - & - \\
\hline Persistência & - & 4 & - \\
\hline Habilidade especial em alguma área específica. & - & - & - \\
\hline Autonomia & - & 15 & - \\
\hline Curiosidade & - & 1 & - \\
\hline Abertura para Experiências. & - & - & - \\
\hline Atitude de correr risco. & - & - & - \\
\hline Humor & 1 & - & - \\
\hline Independência & - & 9 & - \\
\hline TOTAL & 6 & 56 & - \\
\hline Indicadores de Ordem Sociocultural & IPC-Promoção & IIC-Inibição & IPC + ICC no mesmo episódio \\
\hline Construção de Situações Criativas. & 1 & 22 & 1 \\
\hline Função Mediadora bem sucedida da Professora. & - & 21 & 1 \\
\hline Natureza do processo de avaliação do aluno. & - & 3 & - \\
\hline Reconhecimento e valorização do trabalho do aluno. & 1 & 5 & - \\
\hline Cooperação & - & 1 & - \\
\hline Tempo suficiente para as atividades propostas. & - & 13 & - \\
\hline Espaço para rejeição às regras estabelecidas. & - & 3 & - \\
\hline Opções para desenvolver uma atividade. & - & 10 & - \\
\hline Atenção da professora à produção da criança. & - & 11 & - \\
\hline Valorização do Não-Convencional. & - & 6 & - \\
\hline Ameaças ao self. & - & 6 & - \\
\hline Espaço de Autoconhecimento. & - & 1 & - \\
\hline Encorajamento de atitudes criativas pela professora. & - & 14 & - \\
\hline Recursos físicos e materiais adequados. & - & 11 & - \\
\hline TOTAL & 2 & 127 & 2 \\
\hline
\end{tabular}

IPC: Indicador de Promoção de Criatividade; IIC: Indicador de Inibição de Criatividade.

sobre sua produção e ele não respondeu a princípio. Ela insistiu, perguntando se a menina que ele pintava teria ou não um rosto. Breno respondeu sem olhar para PB que ele ia fazer o que PB estava perguntando. Breno, mais uma vez, se retraiu, deixando claro como se sentia intimidado pelas perguntas de PB. Mas por que só Breno foi questionado? Não foi possível identificar os seus motivos e PB desistiu de questionar Breno. Fez-se silêncio na sala de aula. As crianças estavam concentradas nos seus trabalhos. De repente, Breno disse baixinho que a menina tinha nascido com um olho branco e desenhou o olho branco. PB não fez nenhum comentário sobre a 
observação de Breno. Irene disse que iria colocar um foguete na boca, Lili comentou que colocaria um pano. As possibilidades de colocar coisas na boca iam se ampliando. As crianças brincavam com as regras estabelecidas por PB e por elas mesmas. PB não interferia nestas ações, apenas observava e sorria.

Análise do episódio 16. IPC: As crianças brincaram com as regras colocadas por PB e por elas mesmas. PB observou o comportamento das crianças, sorriu das suas ações e não interferiu nos diálogos que surgiram em sala de aula. Ela deixou que as crianças negociassem suas diferenças livremente, por meio do diálogo. IIC: PB, novamente, questionou Breno sobre sua produção, gerando inibição e insegurança no comportamento do garoto. Mesmo tendo sido intimidado, Breno deu uma resposta à PB. Ela, entretanto, não considerou sua resposta nem aproveitou o momento para deixar claro o porquê de sua intervenção na produção de Breno.

$\mathrm{Na}$ Tabela 3 encontramos os resultados dos Indicadores de Criatividade dos Níveis 1 e 2 para a Escola B. PB demonstrou maior competência ao elaborar uma atividade estruturada original e que propiciava oportunidades para os alunos desenvolverem sua criatividade. Embora tenha tido mais sucesso em seu trabalho, PB protagonizou um enorme desperdício de tempo e oportunidades que seriam vitais para o alcance dos objetivos da tarefa.

\section{Entrevistas com as professoras}

As entrevistas foram trabalhadas mediante análise interpretativa (Gaskell, 2003). A partir das respostas dadas pelas professoras aos pesquisadores foram construídas categorias com o propósito de agregar significados acerca das concepções e crenças das professoras sobre a criatividade de modo geral e particular. No total, nove categorias foram criadas. Para fins de ilustração, apenas seis categorias serão apresentadas neste trabalho. Cada categoria será identificada com a sigla "Concepções Relativas à Criatividade ou CRC" seguida de um número.

Concepções relativas à criatividade - CRC (PA e PB). (CRC1) Seus alunos são criativos? Para PA, o aluno criativo é aquele que tem domínio da linguagem oral e escrita, tem boa percepção visual, é estimulado dentro e fora da sala de aula e conta com a participação dos pais em seu processo educativo. Para PB todas as pessoas são criativas. A criatividade é identificada nas falas das crianças, no modo como elas solucionam seus problemas, como administram seus conflitos e como resolvem as questões desafiadoras colocadas em sala de aula. $\mathrm{O}$ aluno criativo é um aluno feliz, mas não está isento de conflitos. (CRC2) Você é uma professora criativa? PA disse se considerar uma professora bastante criativa. Para ela, o professor criativo é aquele que consegue inovar em sala de aula, fugir da rotina e mudar suas práticas pedagógicas. Também é dinâmico, seguro, paciente, extrovertido e perseverante. Na perspectiva de $\mathrm{PB}$, o professor criativo tem uma proposta de trabalho que inclui aprender sempre, buscar resolver questões ao seu modo e criar estratégias próprias a partir do conhecimento adquirido; o professor criativo é aquele que acredita que cada um é cada um e que as respostas dadas pelas crianças, assim com os resultados da aprendizagem, são sempre diferentes, atendendo às singularidades de cada aluno. (CRC3) Sua escola é criativa? PA disse que sim e argumentou que a escola criativa é aquela que desenvolve muitas atividades artísticas, que incentiva seus professores e que adota uma posição aberta. PB não disse nem que sim, nem que não, mas respondeu que a escola criativa prevê a adoção de condutas de investigação e de construção do novo; a escola criativa vê o aluno como construtor do seu próprio conhecimento e é desafiadora. (CRC4) O que é criatividade? Para PA, criatividade consiste em construir alguma coisa usando a imaginação. PA titubeou bastante para dar esta definição de criatividade. Para PB criatividade é a busca de formas interessantes de resolver questões, sejam elas quais forem. Ser criativo é olhar para alguma coisa e repensá-la. (CRC5) Quais atividades desenvolvem a criatividade na escola? Para PA há várias opções: A criatividade pode estar implícita em uma tarefa. Não há necessidade de elementos específicos para o desenvolvimento da criatividade se a tarefa for lúdica, incluir múltiplos materiais e trabalhar alguma dimensão artística. A criatividade é trabalhada quando a criança não precisa copiar nada de ninguém. PB disse que todas as atividades escolares podem desenvolver a criatividade das crianças, desde que conduzidas de modo a incentivar a dimensão investigativa das crianças; a natureza da tarefa não interessa quando o assunto é desenvolver a criatividade, o que interessa é a forma como o professor conduz a atividade. (CRC6) Quais habilidades promovem a criatividade no sujeito? Para PA o que auxilia o desenvolvimento da criatividade é o estímulo que a criança recebe desde pequenina, e quanto mais cedo a criança entrar na escola, mais criativa ela será. Para PB é importante trabalhar a coordenação motora e a orientação espacial, que são habilidades desenvolvidas em tarefas que objetivam fomentar o potencial criativo. 
Tabela 3. Indicadores de Criatividade de Níveis 1 e 2 Presentes ao Longo da Atividade Estruturada por PB ( $\mathrm{n}=20$ episódios)

\begin{tabular}{|c|c|c|c|}
\hline Indicadores de Ordem Cognitiva & IPC-Promoção & IIC-Inibição & IPC + ICC no mesmo episódio \\
\hline Fluência & 3 & - & - \\
\hline Flexibilidade & 3 & - & - \\
\hline Originalidade & 7 & 2 & - \\
\hline Elaboração & 1 & 1 & - \\
\hline Competência para Solucionar Problemas & 5 & - & - \\
\hline Imaginação Combinatória & 15 & 1 & 1 \\
\hline TOTAL & 34 & 4 & 1 \\
\hline Indicadores de Ordem Personológica & IPC-Promoção & IIC-Inibição & IPC + ICC no mesmo episódio \\
\hline Motivação Intrínseca & 15 & 3 & 2 \\
\hline Não-Conformismo & 1 & 2 & - \\
\hline Autoestima & 2 & 2 & - \\
\hline Interesses Amplos & - & - & - \\
\hline Persistência & 2 & - & - \\
\hline Habilidade especial em alguma área específica. & - & - & - \\
\hline Autonomia & 5 & - & - \\
\hline Curiosidade & 10 & 1 & - \\
\hline Abertura para Experiências. & 5 & - & - \\
\hline Atitude de correr risco. & - & - & - \\
\hline Humor & 3 & - & - \\
\hline Independência & 14 & 1 & - \\
\hline TOTAL & 57 & 9 & 2 \\
\hline Indicadores de Ordem Sociocultural & IPC-Promoção & IIC-Inibição & IPC + ICC no mesmo episódio \\
\hline Construção de Situações Criativas & 17 & 2 & 1 \\
\hline Função Mediadora bem sucedida da Professora & 7 & 3 & 9 \\
\hline Natureza do processo de avaliação do aluno & - & - & - \\
\hline Reconhecimento e valorização do trabalho do aluno & - & 2 & - \\
\hline Cooperação & 17 & - & - \\
\hline Tempo suficiente para as atividades propostas & 20 & - & - \\
\hline Espaço para rejeição às regras estabelecidas & 1 & 2 & - \\
\hline Opções para desenvolver uma atividade & 1 & 2 & - \\
\hline Atenção da professora à produção da criança & - & 5 & - \\
\hline Valorização do Não-Convencional & 2 & 1 & - \\
\hline Ameaças ao self & - & 2 & - \\
\hline Espaço de Autoconhecimento & 7 & - & - \\
\hline Encorajamento de atitudes criativas pela professora & 7 & 2 & 1 \\
\hline Recursos físicos e materiais adequados & 1 & 11 & - \\
\hline TOTAL & 80 & 32 & 11 \\
\hline
\end{tabular}

IPC: Indicador de Promoção de Criatividade; IIC: Indicador de Inibição de Criatividade.

\section{Discussão}

A análise dos dados da pesquisa possibilitou identificar e melhor compreender os processos interativos, os contextos, as estratégias e ações comunicativas e metacomunicativas que podem favorecer ou inibir a emergência e desenvolvimento da criatividade (Branco, 2012; Neves-Pereira, 2007). Neste sentido, os Indicadores de Criatividade utilizados foram de excepcional valia. A construção dos IC não só permitiu a análise minuciosa dos dados, em termos de sua frequência, mas especialmente representou um avanço metodológico 
em termos da análise qualitativa da criatividade e seus processos de desenvolvimento.

O discurso de PA acerca da "criatividade" agregava um aglomerado de conceitos sobre o fenômeno criativo retirados do senso comum. Em sua atividade estruturada foi possível identificar como PA desconhecia o significado da criatividade e como atuar para promovê-la. O que se observou foi uma apropriação restrita do conceito de criatividade, com a construção de múltiplos recortes conceituais sobre o tema, gerando, com isto, uma visão inadequada e mal costurada do fenômeno criativo. Considerando todo o conjunto de dados obtidos, pode-se considerar que PA - que segundo a escola era a professora mais criativa do quadro docente - entendia a criatividade como resultante da manifestação de expressões artesanais e artísticas e, quanto mais expostos a atividades desta natureza, mais os sujeitos se tornariam criativos. Atividades como desenho, pintura, teatro, dança, música entre outras, consistiam na chave para a criatividade das crianças. Sem se dar conta, PA trabalhou no sentido contrário ao do desenvolvimento da criatividade em sala de aula, ofertando aos alunos um leque de atividades artesanais, porém com orientações rotineiras, repetitivas e estereotipadas.

PB apresentou uma visão mais profunda e elaborada do fenômeno criativo. Para ela, a criatividade estava vinculada ao repertório interno de cada sujeito e dependia de um contexto favorável para o seu desenvolvimento. A escola poderia prover este contexto ao respeitar a criança, dar-lhe liberdade de expressão e promover um espaço de aprendizagem investigativo capaz de desafiar o aluno para gerar o novo. As ideias de PB encontram ressonância na psicologia de Vygotsky (2009) quando aproxima o ato criativo da realidade e quando considera a imaginação como ferramenta indispensável para a geração do novo. PB se destacou, portanto, como promotora da criatividade de seus alunos, quando comparada a PA. Entretanto, suas competências neste âmbito também apresentaram restrições. Tanto PA quanto PB não trabalharam, em nenhum momento, alguns dos importantes indicadores de criatividade relacionados às dimensões cognitivas, personológicas e socioculturais. PA mostrou desconhecimento em relação ao conceito de criatividade. PB, por sua vez, apesar de demonstrar maior clareza conceitual, deixou de lado inúmeras possibilidades de fomento do potencial criativo de seus alunos no contexto da atividade por ela estruturada.
Foram pouquíssimos os indicadores de promoção da criatividade que apareceram na atividade elaborada por PA. A professora, na prática, atuou basicamente no sentido de inibir a expressão criativa de seus alunos. A atividade escolhida e suas interações com as crianças inibiram as possibilidades de ser criativo em sala de aula. Com relação a PB, na atividade desenvolvida, ela não estimulou Indicadores Personológicos, como interesses amplos (motivação por diferentes áreas do conhecimento), habilidade especial em alguma área específica e atitude de correr riscos, nem Indicadores Socioculturais, como a natureza do processo de avaliação do aluno. Entretanto, todos os indicadores cognitivos foram trabalhados por PB na atividade proposta.

PA apresentou práticas pedagógicas divorciadas do estímulo ao potencial criativo em sala de aula. Sua atividade estruturada atuou, literalmente, no sentido de inibir o potencial criativo das crianças, embora ela achasse justamente o contrário. Sua prática traduziu suas concepções, mostrando o desconhecimento da professora acerca do tema criatividade. Entretanto, PA não compreendeu seu esforço desta maneira. Ela deixou claro na entrevista que tinha alcançado seu objetivo sim. PA não se percebeu inibindo a criatividade das crianças, pelo contrário, viu-se na função oposta. Considerada a professora mais criativa da Escola A pela coordenação, ela não estava disposta a abdicar deste título. PA não se deu conta de seu equívoco, pois desconhecia as características do fenômeno criativo e de um ensino voltado para o seu desenvolvimento. PB também cometeu alguns deslizes. Embora suas concepções e práticas com relação à criatividade se aproximassem mais dos conceitos difundidos na literatura, ela algumas vezes inibiu o potencial criativo das crianças, mas não se deu conta disto. Em resumo, as concepções e crenças das professoras definiram práticas pedagógicas, demonstrando claramente o quanto estas significações internalizadas com base em processos de canalização cultural são eficientes em orientar suas ações e interações (Beghetto \& Kaufman, 2010; Nickerson, 2010; Valsiner, 2012a, 2012b). Crenças equivocadas sobre processos de desenvolvimento humano, aprendizagem e funções psicológicas podem, portanto, levar profissionais sérios e comprometidos a práticas inadequadas, incompatíveis com os objetivos que se deseja alcançar. 


\section{Considerações finais}

A metodologia adotada no presente estudo foi muito produtiva no sentido de revelar fatores impeditivos e facilitadores do desenvolvimento da criatividade no ambiente de sala de aula. Estes fatores, como as características e regras de participação social das atividades, ações e verbalizações no contexto de interações comunicativas e metacomunicativas, somente se tornaram visíveis mediante a avaliação minuciosa e detalhada dos significados culturais em coconstrução, que é típica da análise microgenética aqui empregada.

Observamos no estudo que o domínio de saberes pedagógicos consistentes e progressistas não foi suficiente para que o professor estimule o desenvolvimento da criatividade. Foi o caso de PB, considerada excelente professora no contexto de uma escola de vanguarda. PB era, sem dúvida, uma professora competente, mas que parecia não dominar conteúdos específicos sobre a criatividade como fenômeno desenvolvimental. É necessário que a criatividade e seus processos de desenvolvimento sejam especificamente considerados no contexto educacional, trabalhados em termos conceituais e em termos de práticas pedagógicas orientadas para o seu fomento (Beghetto \& Kaufman, 2010).

Uma conclusão importante merece especial destaque. O professor pode, muitas vezes, enganar-se com relação a sua própria prática e não perceber que está atuando no sentido oposto ao desejado. Assim sendo, é preciso um trabalho específico visando desenvolver no professor a capacidade de observar e analisar a estrutura das atividades que seleciona e como as suas interações com as crianças podem estar contribuindo ou dificultando o alcance dos objetivos propostos. Preparar um professor para promover o ensino criativo não consiste apenas em prover conhecimentos acerca da criatividade, mas, principalmente, trabalhar as suas crenças sobre como as crianças se desenvolvem, e de que forma.

Para finalizar, vale destacar a importância que Valsiner (2012a, 2012b) dá aos processos semióticos que são absolutamente centrais na compreensão da constituição psicológica do sujeito, sua emergência e seu desenvolvimento em contextos socioculturais específicos. É este conhecimento que permitirá aos educadores efetivamente implantar práticas pedagógicas que produzam os resultados desejados em termos do desenvolvimento da criatividade em crianças, jovens e adultos.

\section{Referências}

Amabile, T. M. (1996). Creativity in context. Boulder, CO:Westview Press.

Batey, M., Furnham, A., \& Safiullina, X. (2010). Intelligence, general knowledge and personality as predictors of creativity. Learning and Individual Differences, 20(5), 532-535. doi: 10.1016/j. lindif.2010.04.008

Beghetto, R. A., \& Kaufman, J. C. (2010). Broadening conceptions of creativity in the classroom. In R. A. Beghetto \& J. C. Kaufman (Orgs), Nurturing creativity in the classroom (pp.191-205). Nova lorque: Cambridge University Press.

Branco, A. U., \& Valsiner, J. (2012). Cultural psychology of human values. Charlotte, NC: Information Age Publishing, INC.

Connery, M. C., John-Steiner, V. P., \& Marjanovic-Shane, A. (2010). Vygotsky and creativity. A cultural-historical approach to play, meaning making, and the arts. Nova lorque: Peter Lang Publishing.

Eysenck, H. J. (1997). Creativity and personality. In M. A. Runco (Org.), The creativity research handbook. (pp. 41-66). Cresskill, NJ: Hampton Press.

Gaskell, G. (2003). Entrevistas individuais e grupais. In M. W. Bauer \& G. Gaskell (Orgs.), Pesquisa qualitativa com texto, imagem e som. Um manual prático. (pp. 64-89). Petrópolis: Vozes.

Hoff, E. V., \& Carlsson, I. (2011). Teachers are not always right: links between teacher ratings and students' creativity scores, self-images and self-ratings in school subjects. The Open Education Journal, 4, 120-129. doi: 10.2174/1874920801104010120

Kosulin, A. (1994). La psicologia de L.S. Vygotsky. Madri: Alianza.

Lindqvist, G. (2003). Vygotsky's theory of creativity. Creativity Research Journal, 15, 245-251. doi: 10.1080/10400419.2003.9651416

Neves-Pereira, M.S. (2007). Uma leitura histórico-cultural dos processos criativos: as contribuições de Vygotsky e da psicologia soviética. In A. M. R. Virgolim (Org.), Talento criativo. Expressão em múltiplos contextos (pp. 65-85). Brasília: Editora da Universidade de Brasília.

Nickerson, R. S. (2010). How to discourage creativity thinking in the classroom. In R. A. Beghetto \& J. C. Kaufman (Orgs), Nurturing creativity in the classroom (pp. 1-5). Nova lorque: Cambridge University Press.

Rogoff, B. (2003). The cultural nature of human development. Nova Iorque: Oxford University Press.

Smolucha, F. (1992). A reconstruction of Vygotsky's theory of creativity. Creativity Research Journal, 5(1), 49-67. doi: 10.1080/10400419209534422

Tardif, T.Z., \& Sternberg, R. J. (1988). What do we know about creativity? In R. J. Sternberg (Org.), The nature of creativity (pp. 429-440). Nova Iorque: Cambridge University Press.

Valsiner, J. (2012a). A guided science. History of psychology in the mirror of its making. Nova Jersey: Transaction Publishers.

Valsiner, J. (2012b). Fundamentos da psicologia cultural. Mundos da mente. Mundos da Vida. Porto Alegre: ARTMED.

Vygotsky, L.S. (2009). A imaginação e a arte na infância. Lisboa: Relógio D’Água. 
Criatividade na educação infantil: contribuições da psicologia cultural para a investigação de concepções e práticas de educadores

Mônica Souza Neves-Pereira, Doutora em Processos de Desenvolvimento Humano e Criatividade pelo Instituto de Psicologia da Universidade de Brasília, é Professora Adjunta do Departamento de Psicologia Escolar e do Desenvolvimento no Instituto de Psicologia da Universidade de Brasília. Endereço para correspondência: Instituto de Psicologia - Universidade de Brasília - UnB. Campus Universitário Darcy Ribeiro, Brasília - DF, 70910-900. Telefone: (61) 3107.6888 - 3107.6830. E-mail: monicasouzaneves@gmail.com.br

Angela Uchoa Branco, Doutora em Psicologia pela USP (São

Paulo), Pós Doutorados na University of North Carolina (USA), na Duke University (USA) e naUniversidad Autonoma de Madrid (Espanha), é Pesquisadora Colaboradora na Universidade de Brasília. E-mail: ambranco@terra.com.br 